\title{
Atlantis
}

Critical Studies in Gender, Culture \& Social Justice

Études critiques sur le genre, la culture, et la justice

\section{The Benefits and Burdens of Engaging in Argumentation: Trans*feminist Reflections on Tuvel's "In Defense of Transracialism"}

\section{Stephanie Kapusta}

Volume 39, numéro 2, 2018

URI : https://id.erudit.org/iderudit/1064073ar

DOI : https://doi.org/10.7202/1064073ar

Aller au sommaire du numéro

Éditeur(s)

Mount Saint Vincent University

ISSN

1715-0698 (numérique)

Découvrir la revue

Citer cet article

Kapusta, S. (2018). The Benefits and Burdens of Engaging in Argumentation: Trans*feminist Reflections on Tuvel's "In Defense of Transracialism". Atlantis, 39(2), 61-73. https://doi.org/10.7202/1064073ar
Résumé de l'article

After considering some ways of assessing argumentation, I present an ethical assessment of Tuvel's argument in her article "In Defense of Transracialism." My claim is that some transgender women engaging with Tuvel are exposed to certain kinds of injustice associated with argumentational work, namely, disproportionate burdens and risk of psychological harm. 


\section{The Benefits and Burdens of Engaging in Argumentation: Trans*feminist Reflections on Tuvel's "In Defense of Transracialism"}

Stephanie Kapusta is a Visiting Assistant Professor in the philosophy department, and Interim Coordinator of the Law, Justice and Society Program in the Faculty of Arts and Social Sciences at Dalhousie University, Nova Scotia. Her principal research interests lie in feminist philosophy, and social and political philosophy, with an emphasis on trans* studies. She has published, among other pieces, articles on misgendering in Hypatia ("Misgendering and its Moral Contestability") and on the indeterminacy of sex predicates in Topoi ("Imposing Sex Predicate Indeterminacy"). She has also written a forthcoming entry in the International Encyclopedia of Ethics (Wiley) on "Transgender Rights," and a soon-to-appear article in the Australasian Philosophical Review on "The Social Practise of Cognitive Estrangement." Stephanie gave a recent interview ("Trans*feminism: How Trans Issues and Feminism Overlap") for the Blog of the American Philosophical Association (APA Blog Interview). She loves trees and fall colours, good Sci-Fi movies, and singing.

Abstract: After considering some ways of assessing argumentation, I present an ethical assessment of Tuvel's argument in her article "In Defense of Transracialism." My claim is that some transgender women engaging with Tuvel are exposed to certain kinds of injustice associated with argumentational work, namely, disproportionate burdens and risk of psychological harm.

Keywords: argumentation; argumentational injustice; transgender; Rebecca Tuvel; misgendering
The Hypatia controversy surrounding Rebecca 1 Tuvel's article "In Defence of Transracialism" elicited a flurry of responses on social media and in the press (Bettcher 2017a; Dutta 2017; Oliver 2017; Schuessler 2017; Singal 2017; Winnubst 2017). In her article, Tuvel defended a rather strict analogy between gender transition and "transition to another race" (Tuvel 2017a, 272). Many scholars have denied the validity of that analogy, either on philosophical grounds or sociological ones (for example see Borck 2017; Sealey 2018). Despite the fact that a whole philosophy journal issue has been dedicated to the controversy (Philosophy Today 2018, 62.1), both in journal articles and on social media there has been relatively little philosophical assessment of the trans-exclusionary implications of the content and method of Tuvel's argumentation, particularly for transgender women. ${ }^{1}$ This may not be surprising, for two reasons. First, Tuvel's claims concerning race and racial "transitions" are the focus and most prominent (as well as controversial) aspects of the article. Second, Tuvel adopts an explicitly trans-positive approach, especially in her express commitment to respect transgender identifications, and to regard them as legitimate (Tuvel 2017a). It might then appear that the article is unequivocally trans(gender)-inclusive.

My goal in this contribution is to engage with Tuvel's article on the question of the trans-exclusionary and marginalizing implications of some of her assumptions. Much of that trans-exclusionary thrust emerges from Tuvel's use of Haslanger's definition of woman (Haslanger 2012). After the controversy her article generated, Tuvel admitted that she "could have spent more time grappling with the criticisms of Haslanger's view" (Tuvel 2017b), so the present article might appear as nitpicking, an attempt to dwell on a matter that has already been addressed. However, an essential 
and original part of my project is to locate Tuvel's paper within a broader context of much traditional philosophical practice that creates conditions of injustice for professional philosophers who belong to marginalized groups. I can second-and wish to expand upon-Talia Bettcher's (2017a) sentiment that the controversy is not just about Tuvel's article, but presents a broader issue for philosophy, particularly a certain traditional way of doing philosophy which focusses on the logical-epistemic goals of argumentation, and on the subsequent assessment of argumentation in light of these goals. In contrast, an ethical assessment of argumentation reveals that at least some practices of professional philosophy expose members of marginalized groups to injustices. More specifically, I illustrate how Tuvel's article instantiates this type of injustice with respect to at least some transgender women who engage professionally with her argument. I do not contend that this is because of Tuvel's analytic approach in her article, nor that analytic argumentation generally leads to injustices within argumentational exchanges (Botts 2018; cf. Tuvel 2018). In fact, I employ analytic methods myself in this article. The problems lie elsewhere, as I hope will become clear. $^{2}$

In the next section, I briefly discuss two main ways in which we can assess philosophical argumentation: logical-epistemic assessment, and ethical assessment. I then set up a framework in which to understand professional argumentation as work with associated goods and burdens. Just as in any work, there are "bads" to be avoided in the content and in the way the work is structured, and goods that are legitimately expected by those who undertake the work. I then argue that the burdens of argumentation considered as work may be relatively greater in some cases for professional arguers with particular identities or who are members of particular marginalized groups. Tuvel's article then serves as an example of how this additional burdening can happen. After anticipating some objections to my view, I end with some general remarks regarding the eradication of injustices within professional argumentation.

\section{The Logical-epistemic Perspective and the Ethical Perspective on Argumentation}

At some risk of over-simplification, I think one can locate several broad responses to Tuvel's article according to whether a more "logical-epistemic" or a more "ethical" assessment of her argumentation is adopted. The former type of assessment has been the more traditional approach within Anglo-American analytic philosophy. It considers arguments from the perspective of such measures as justification, rationality, and convergence upon truth. In his New York Magazine article, for example, Jesse Singal writes:

Anyone who has read an academic philosophy paper will be familiar with this sort of argument. The goal, often, is to provoke a little-to probe what we think and why we think it, and to highlight logical inconsistencies that might help us better understand our values and thought processes. This sort of article is abstract and laden with hypotheticals - the idea is to pull up one level from the real world and force people to grapple with principles and claims on their own merits, rather than-in the case of Dolezal-baser instincts like disgust and outrage. This is what many philosophers do. (Singal 2017)

In a similar vein, Justin Weinberg, editor of the philosophy blog Daily Nous, says of Tuvel's article, "in terms of quality, it's a very normal paper" (quoted in Schuessler 2017).

In contrast, in a Chronicle of Higher Education piece, Shannon Winnubst adopts an "ethical" assessment. She focusses far more on the social position of the potential addressees of Tuvel's reflections. She states:

After all, the methodological insularity evidenced in Tuvel's article and its publication effectively render ignored and disrespected black, trans, and other minority scholars who work in these fields doubly marginalized. The inequalities perpetuated are both conceptual and practical. (Winnubst 2017)

I will consider these two ways of normatively assess- 
ing argumentation more closely. They are not mutually exclusive, and the way I describe them should be regarded as "bare bones" accounts of each.

Roughly speaking, an argument is usually taken to be a set of propositions. One or more of these propositions provides rational support for a particular proposition of the set, the conclusion. Argumentation is the dialectical exchange of reasons for or against a proposition (thesis). The exchange can take written or oral form. The logical-epistemic perspective considers argumentation in itself, looking at the inherent goals and standards of arguing, assuming that arguers are generalized rational arguers, considered in the abstract. Whatever else those arguers may be is irrelevant to the assessment of argumentation (Bondy 2010).

Logical-epistemic assessment of argumentation considers the various "intrinsic" goals that argumentation serves and assesses a given argument or arguments in light of such goals understood as standards or criteria for "good" argumentation. For example, it is generally accepted that converging on truth (however conceived), or justifying and rationally persuading, are among such intrinsic goals (Bermejo-Luque 2011; Johnson 2000; Micheli 2012;). These goals of argumentation can be used to evaluate arguments and arguers in a functionally normative way; one asks whether-and how well-the arguments presented have fulfilled one or more of these intrinsic goals.

Another possible type of assessment of argumentation focusses more on "extrinsic" factors. Of course, what is and is not "extrinsic" in the case of argumentation depends on the goal of the exchange of reasons, the degree of theoretical abstraction that one is willing to perform, and on what one regards as appropriate to abstract away from. Generally, the goals of argumentation in extrinsic assessment are considered as far more dependent on the context of argumentation, including the more particular interests of the arguers. Within negotiation, for example, the goal may be to reach a deal between parties with conflicting interests; within deliberation, the extrinsic goal of argumenta- tion is to choose and execute a particular course of action (Paglieri and Castelfranchi 2010; Walton and Krabbe 1995; cf. Mohammed 2016). Other goals are of a political or ethical nature. Such goals will be my main focus in what follows.

Within philosophy in particular, argumentation has been critiqued from an ethical point of view as regards both method and style. There has been criticism of Anglo-American philosophy's practices of idealization, to the exclusion of actual social hierarchies and oppressions (Berenstain 2018; Mills 2005; various contributions in Tessman 2009). This kind of critique can be viewed as "extrinsic" in that it focusses on the way western philosophical argumentation has developed under the influence of particular historical schemas or narratives (Peńa-Guzmán \& Spera 2017), such as the recurring "argumentation-as-war" metaphor (Rooney 2010). This is a sociohistorical critique. However, the implication of such critique is usually that philosophy as currently practiced is morally or politically questionable since its historical self-conception-as mirrored in its practices and institutions-is exclusionary of certain types of people, such as women. Although I do not take up sociohistorical approaches here, I will also point to exclusionary tendencies in Tuvel's argumentation.

More directly relevant to my limited project in this article is the moral status of participants as rational arguers, or-if argumentation is viewed as a process for establishing true beliefs - as contributors to knowledge. There has been much recent interest within philosophy in epistemic injustice. This type of injustice occurs when members of marginalized groups suffer prejudiced credibility deficits (testimonial injustice) or prejudiced intelligibility deficits (hermeneutical injustice) in their status as contributors to knowledge (Fricker 2013; McKinnon 2016). The former are injustices that occur when someone's testimony is not granted the due credibility it deserves, simply on the basis of the person's social position. The latter is a result of the fact that oppressed members of society have very little influence on the concepts, theories, and terminology used to describe experiences that are partic- 
ularly in their interests to express. They are marginalized within the process of discursive resource production (hermeneutical marginalization) which then has the effect that when they do actually attempt to express their experience of oppression, they are unintelligible to the dominant group. This intelligibility deficit is hermeneutical injustice. Testimonial and hermeneutical injustices are closely linked to testimonial quieting (Dotson 2011) in which members of oppressed groups are silenced through dismissal of their testimonies or else are constrained to adopt discourses that do not fully reflect their experience. This adoption occurs in the face of harmful ignorance, prejudice, or bias that shape the receptive competence of their audiences.

Bondy (2010) has applied the notions of testimonial injustice to argumentation, in what he calls "argumentative injustice." Bondy argues that in argumentation both credibility deficit and excess endanger one of the goals of argumentation, namely, the justificatory "force of reason" alone. There are three ways in which this goal is frustrated. First, due to prejudicial imbalances in credibility (and authority) among the parties in a debate, the arguments that the respective parties proffer are not considered as they should be by the lights of logical-epistemic normativity. Second, the status as arguer within the community of arguers is diminished through credibility deficit or enhanced through credibility excess. In either case, members of the community cease to engage with proffered reasons in the way they should: they will either tend to "not bother" with the arguments of those perceived to have poor arguer status or accord too much authority to those who have enhanced status, simply assuming that they are correct. Third, those who suffer credibility deficits will lose confidence and self-esteem as arguers and tend to withdraw from argumentation. Those who enjoy credibility excess will become over-confident and not engage with others at all, or not as seriously as they should (Bondy 2010). So, arguments, the external perception of arguers, and their self-perception are all affected by prejudicial credibility defects and excess. The rationality of their exchange is defective as a result.
Bondy considers how an "intrinsic" good of argumentation, the force of rational justification, fails to be realized because of epistemic injustice. He focusses, namely, on the detriment caused to the normative, rational nature of argumentation: unjustly accorded credibility deficits and excesses cause reasons to lose the force that they should have. At first sight, it seems that Bondy's assessment is purely logical-epistemic. Yet this impression arises only because he considers the further logical-epistemic consequences of what are-in the first instance-harms that possess a distinctly moral nature. For undeserved, prejudiced diminishment of arguer status within a community of arguers is a moral harm, a type of disrespect. Moreover, if we accept that attributed credibility excess to members of dominant groups is "contrastive" (Medina 2011) then credibility excess accorded to some will likely cause credibility deficits suffered by others, by members of subordinate groups, leading to similar moral harms. It is this relative diminishing and enhancement of status between marginalized and socially dominant or privileged arguers that is, to my mind, the primary moral harm. The primary harm then leads to logical-epistemic harms (failure of rationality) as well as to other moral harms (lack of selfesteem, exclusion). One might note, by way of addition, that further moral harms for the marginalized arguers also include the limitation of "epistemic agency, one's ability to pursue epistemic projects, and epistemic autonomy, one's ability to pursue epistemic projects that stem specifically from one's distinct lived experience" (Pohlhaus 2014, 110).

My own approach to the assessment of argumentation engagement with Tuvel (2017a) is related to the secondary moral harms that authors such as Fricker, Dotson, Medina, Pohlhaus and Bondy discuss-loss of self-respect, loss of epistemic confidence or excessive epistemic confidence, various forms of silencing-but the primary injustice is different. The primary injustice consists in the following: the content or structure of the argumentational exchange itself places disproportionate burdens on socially marginalized arguers or exposes them to the risk of psychological harms. There need be no denial of credibility, yet the second- 
ary effects can be similar; cognitively burdened arguers will find their self-esteem can be affected, and they may exclude themselves from debates that are of vital interest to them. To distinguish this notion of injustice from Bondy's I will use the generic term "argumentational injustice," of which "argumentative injustice" (involving prejudicial credibility deficits and excess of which Bondy speaks) is just one type. The two types of injustice I analyse in what follows are also types of argumentational justice, but distinct from Bondy's. One involves disproportionate cognitive burdens that arise due to social position. The other involves risk of psychological harm. Both arise from engaging with arguments within an exchange of reasons (that is why they are "argumentational" injustices). In the next section, I give a brief account of these injustices.

\section{The Burdens of Argumentational Work and Associated Injustices}

Nora Berenstain considers a type of labor that I believe argumentation, as I conceive it, may involve. Particularly when challenged to explain the nature of their own oppression, members of oppressed groups perform a kind of discursive labor that can be exploitative, in that it is largely "unrecognized, uncompensated, emotionally taxing" (Berenstain 2016, 569). Inasmuch as explanations or testimonies of this sort can be elements of proffering reasons within an argumentational exchange, Berenstain's notion of exploitative labor can also apply to argumentation. However, in contrast to Berenstain, I assume that participants in argumentational exchange do not engage in argumentation in bad faith, are genuinely willing to listen and to learn, and do not seek to take credit for arguments that are not their own. That said, I point out that there may still be additional, uncompensated burdens for some transgender women as they engage with Tuvel's argument.

In this kind of context, argumentational practice is work, work that encompasses the activities of study, the coherent and precise formulation of propositions (such as theses and definitions), the invention of ar- guments and counter-arguments, the posing of incisive questions and challenges to theses and arguments, and so forth. This work will also devote itself to verbal expression, such as trying to find the precise and clear formulations for thoughts and arguments. As from work in general, one is entitled to expect certain nonmonetary "goods" of work, such as excellence in performing relevant tasks, social status, community and collaboration, and a sense of self-respect (Gheaus and Herzog 2016). However, argumentational work-like any work-also comes with burdens.

Some philosophical arguments are more difficult and more complex than others. If those who consider and try to understand those arguments and those who develop them are equally intelligent and possess the same argumentative acumen (an assumption I will make), we can say that some arguments require more cognitive effort than others. We are talking about what one might call the cognitive burdens of argumentational work.

Yet, these are not the only burdens that come with engaging in philosophical argumentation. Consider, for example, ethics or political philosophy, or the philosophy of gender and race, the disciplinary focus of Tuvel's article. In these fields, one is more likely to discuss questions concerning identity, oppression, injustice, and marginalized groups. This, in turn, will mean that some philosophers have an acute interest in presenting or disputing arguments that treat their own identity, oppression, or marginalization. That interest arises because these philosophers are existentially invested in presenting and correctly analyzing the injustices to which they themselves, as members of marginalized communities, are exposed. It is thus an over-simplification to consider merely the cognitive costs of engaging in certain arguments. There may also be significant emotional costs of some form. I will not attempt to neatly distinguish the "purely" cognitive realm from the emotional realm in relation to argumentative burdens, and simply call all these burdens "the burdens of argumentational engagement" (BAE). The burdens involved are relative to a particular person in the ways indicated above and are 
also relative to the subject matter and goals of an argument. What one wishes to argue for (or against), the number of argumentative steps one needs to get there, as well as the emotional burden one bears in doing so, will influence the BAE.

Exposing someone to harm within an argumentational exchange is the second type of injustice I wish to consider. In any collaborative venture undertaken to secure important, common goods or benefits - and I take argumentation to be such-increased exposure of one party to harm on the basis of their identity or social position is an injustice. Below, I focus on the risk of the psychological harm of misgendering which, considered as a microaggression, has been shown to cause harmful psychological effects (Sue 2010; Nordmarken 2014; Kapusta 2016; PuliceFarrow, Clements \& Galupo 2017). My claim is not that such harms necessarily occur within argumentational work but that there is an unwarranted selective exposure of some of the arguers to the risk of these harms, and this exposure occurs due to the fact that they are members of a marginalized group, that is, socially situated within systems of subordination.

In summary, here are two types of injustice that can occur within argumentational work:

(i) Those who, due to morally irrelevant factors, in particular their social position, have to bear a relatively higher burden of argumentational engagement (BAE) in securing the goods of argumentational work, suffer an injustice. For example, one's gender identity or membership in a marginalized group is a morally irrelevant factor. If BAE is relatively higher due to such factors, an injustice occurs. This is a version of a "benefits and burdens principle": all other things being equal, those who collaborate towards similar goods (benefits) of work should be equally burdened. I will call this injustice "disproportionate BAE."

(ii) Like any work, argumentational work is unjust if it exposes arguers to the risk of psychological harm, on the basis of their social position. I will call this "harm injustice." 3
Let us now turn to a more detailed analysis of Tuvel's argument to see how her article risks inflicting the above injustices on trans women as they engage with it.

\section{The Transgender Burdens in Rebecca Tuvel's "In Defense of Transracialism"}

I will point out the implicit misgendering in Tuvel's article, the manner Tuvel deals with it, and consider its microaggressive character. Misgendering occurs, I claim, because some trans women who engage with Tuvel's argument are denied membership of the class woman or, from the point of view of offering reasons within an argumentational exchange, it is at least left undecided or indeterminate whether they are women or not. It is worth noting that the misgendering is inferential, that is, the transgender woman must engage with Tuvel's argument argumentationally to realize that she is being misgendered. This is an important aspect of this type of argumentational injustice. It is not the case that excesses of deficits of credibility diminish rational engagement with arguments, thus resulting in rationality deficits. Quite the opposite: it is through engagement with reasons, that is, through the drawing of inferences from the claims and arguments put forward that the misgendering occurs. ${ }^{4}$

As regards the injustices involved in such a situation, one can say that since misgendering imposes emotional burdens on the transgender woman that cisgender arguers do not bear, disproportionate BAE occurs. Further, inasmuch as insistent misgendering is a microaggression or micro-invalidation (Sue 2010), there is also a risk of harm injustice.

At the beginning of her discussion of the moral acceptability of racial self-identifications, Tuvel states the general principle that "we treat people wrongly when we block them from assuming the personal identity they wish to assume" (Tuvel 2017a, 264). In the final section of her article, and in the accepted style of philosophical argumentation in the analytic tradition, Tuvel then anticipates an objection to her general argument. The objection is that Tuvel's ac- 
count of race and gender based on self-identification seems far too permissive. What, after all, is to stop someone self-identifying as a wolf, for example, or some completely other being? Are we to respect such a self-identification? No, says Tuvel, and she suggests the following moral constraint on the recognition of self-identities:

It is reasonable for a society to accept someone's decision to enter another identity category only if it is possible for that person to know what it's like to exist and be treated as a member of category X. Absent the possibility for access to what it's like to exist and be treated in society as a black person or as a man (or as an animal), there will be too little commonality to make the group designation meaningful. For example, if a cisgender white man fights for his rights not to be subject to antiblack police violence or to misogyny, yet never faces the possibility of having his rights so violated, we can reasonably expect allyship, not identification, from him. (272)

Tuvel thus espouses the following constraining principle on the recognition of people's self-identification that I define as PossibleKnowledge:

PossibleKnowledge: For x's self-identification with a gender category $\mathrm{g}$ or with a race category $\mathrm{r}$ to be ethically acceptable, it must be possible for $\mathrm{x}$ to know what it is like to exist and be treated as a member of $g$, respectively of r.

Tuvel is expressing a condition for the reasonableness or ethical acceptability of a gender or racial self-identification. But it is important to realize how this condition combines argumentatively with Tuvel's endorsement of Sally Haslanger's definitions of gender and race (Tuvel 2017a, 273-4). Let us focus on the perspective of trans women. Haslanger defines a woman as follows:

$S$ is a woman if $S$ is systematically subordinated along some dimension (economic, political, legal, social, etc.), and $S$ is "marked" as a target for this treatment by observed or imagined bodily features presumed to be evidence of a female's biological role in reproduction. (Haslanger 2012, 230; 250)

Tuvel sees in this definition the potential for including trans women in the definition of woman. The reason for this is that the bodily features Haslanger mentions in her definition need only be imagined. To be a woman, a transgender woman does not actually have to possess vagina, ovaries, or a uterus, for example. In Tuvel's argument, PossibleKnowledge-combined with Haslanger's definition (let us call the combination PossibleKnowledgeFromSocialPerception) - requires only that it be possible that the transgender woman be socially perceived as possessing female sexual characteristics, thus be classified as a woman, and so know what it is like to be so classified. If this chain of events ensues, her self-identification is reasonable or ethically acceptable.

However, Haslanger's definition of woman has been critiqued for its trans-exclusionary character (Jenkins 2016). [5] That critique points out that Haslanger excludes from the category woman those transgender women who are not perceived as being in possession of female reproductive organs. In an endnote-and almost as an afterthought-Tuvel acknowledges this critique and simply states that she is open "to the possibility that there might be ways to know what it's like to exist and be treated as a woman without being so classed by others" (Tuvel 2017a, 276-77). She does so, presumably, to avoid the conclusion that the gender self-identifications of trans women who do not "look" female or are not generally considered within society to be capable of female role in reproduction, are not morally acceptable. For without this caveat, this is what PossibleKnowledgeFromSocialPerception would imply.

Tuvel thus seeks to avoid misgendering these trans women. Yet, there is scope for injustice in any argumentational engagement by trans women with Tuvel's article:

(i)Disproportionate $B A E$. "Filling in the argument"-that is, showing how it is possible to 
know what it is like to exist and be treated as a woman without being so classified, without "passing" as a cisgender woman-is postponed to a later date, and left simply as a claim assumed to be rationally arguable. From the point of view of reasons proffered, it is left undecided, indeterminate. Yet, it is particularly in the interest of the transgender women whose self-identifications are deemed morally questionable due to PossibleKnowledgeFromSocialPerception that this additional argumentative step be made. Of course, trans women who are located at intersectionally precarious social positions are particularly affected. These include trans women of colour who cannot present the hyper-sexualized object of the racist gaze and so cannot count as women in a racist culture, or disabled trans women arguers, for whom it is more difficult to perform the gender codes of society, and thus to be treated as a member of the category of women (cf. Clare 2009). Or it may be the transgender woman who cannot be viewed socially as a woman due to socio-economic class, especially if hormonal and surgical interventions are expensive or access to them is restricted. Older trans women who transition in later life, when hormones do not have the same "feminizing" effects, are also particularly vulnerable to this inferential misgendering as they engage with the article: These women are at worst inferentially labelled as not women; at best their being women is left undecided. In either case, there will be a sense of alienation and sense of lack of respect for their personal struggles. An emotional burden is born that cisgender persons will not experience when engaging with the same argument.

(ii) Harm Injustice. The transgender woman philosopher who is not viewed (classified) as a woman within her social environment realizes that she is implicitly misgendered as she engages with Tuvel's argument. This may not, in itself, cause significant psychological harm. But allied to the probable misgendering of these people in their own society, as well as a certain "tradition" in the philosophy of gender that is known to have been trans-exclusionary (Kapusta 2016; Jenkins 2016; Bettcher 2017b), there is a danger of cumulative microaggressions (Sue 2010; Nordmarken 2014; PuliceFarrow, Clements \& Galupo 2017). These can cause actual psychological harms within the professional community for trans women who engage with this material. (I leave it as an exercise for the reader to analyse how harm injustice or disproportionate BAE might arise from engaging with passages from Bach (2012, 269); with Mikkola's "equivocal cases" of woman (2009, 578 ff.); with Witt's vacillations regarding "third gender" conceptions of trans people-including, presumably, trans women (2011, 41); with Zack's disjunctive definition of woman (2005); and with Alcoff's womandefining "relationship of possibility to biological reproduction" (2006, 172)). The continued misgendering of "non-passing" transgender women can amount to repeated microaggression. Moreover, in more extreme cases, some transgender women's self-respect may be undermined.

\section{Some Objections and More Points to Ponder}

Let me anticipate some objections to my analysis. First, one objection might consist in claiming that the transgender population I have been considering is very small. Perhaps there are-in point of fact-no transgender women arguers who are affected by injustices in the way I have described. First, there may in fact be no argumentational engagements by transgender women inferentially misgendered by arguments of the type I have described. Second, philosophers or professional arguers may be more psychologically robust than most, so that the misgendering does not impose the burdens I have spoken of. However, even if there were, in fact, no such engagements by transgender women with arguments like Tuvel's or relevantly similar to Tuvel's, the risk of in- 
justice or the potential threat of injustice is, itself, a moral wrong. In response to the second point, the anticipated objection portrays the philosopher as an idealized rational agent, unperturbed by her social position or marginalization. If really proffered as an objection to my argument, it would reflect the image of a disembodied, unemotional, unfeeling ideal of the philosopher, a completely unrealistic portrayal, but also one with sexist and misogynistic undertones (Реńa-Guzmán and Spera 2017; Berenstain 2018).

It might be claimed that even if the transgender women I speak of suffer injustices in the ways I have indicated, they nevertheless always retain the option of simply not engaging with Tuvel's article. However, simply foregoing argumentational engagement with Tuvel and other authors is a kind of "argumentational smothering" akin to testimonial smothering (cf. Dotson $2011 ; 2014,127)$. Such a solution also causes harms. First, there is the political harm of exclusion: professional arguers who are transgender would tend to exclude themselves from a discussion or even a given sub-discipline, and the latter would then fail to be or become trans-inclusive. Second, this solution arguably brings a logical-epistemic harm given that increased diversity of arguers opens professional argumentation up to the insights of marginalized persons and provides a corrective for misconceptions.

Relatedly, one could suggest that the injustices are certainly possible but easily mitigated or eliminated through the organization of academic argument. For example, there might be some unwritten convention that only marginalized persons should take part in debates that directly touch upon their identities or situation. This solution would-so the thought goes-help to avoid the misgendering or other exclusionary practices that relatively privileged professional arguers have been known to engage in. However, such a practice is also morally problematic. First, members of the profession would be implicitly constrained to "out" themselves. Moreover, it would lead to a kind of "sorting" of people within the academic profession according to their identities or social status. Even if such policy were implementable, it could lead to morally, politically-and perhaps epistemically-undesirable effects of another kind. Philosophers from minority or marginalized groups might feel burdened to undertake work in these areas rather than, for example, in the philosophy of physics or some other area where their creativity and argumentational acumen is better served, and more fruitful to the community. Their professional autonomy and academic freedom would, thereby, be impaired, and their work, perhaps, less productive.

A further objection might concern the perspective I have taken of the risk of exposure to injustices for individual professional arguers who belong to marginalized groups. Perhaps one should—so the objection goes-look at longer-term consequences of such debates. It may turn out, for example, that the philosophical profession as a whole and in the longer term benefits from these argumentational exchanges, even if marginalized individuals who contribute to them are subject to emotional harms or disproportionate BAE. For example, the professional practitioners of philosophy may become more aware and better informed about their colleagues from marginalized groups and alter their practices accordingly. With time, philosophy will become more diverse, both with regard to its professional membership, as well as with regard to its methods and practices.

Responses to this objection will vary depending on fundamental convictions regarding normative ethics. A utilitarian approach might lead one to the conclusion that a greater aggregate and long-term benefit is furthered by the engagement of marginalized individuals in professional argumentation, and therefore ethically justified, even if some marginalized individuals suffer by being disproportionately burdened, psychologically harmed, or "sacrificed" in some other way. Let me simply note that I place the emphasis on individual dignity and equality. In line with this idea, a harm experienced by an individual is not usually justified by invoking an aggregate or general, longterm benefit. Even if social progress often occurs in this mode of individual sacrifice, that does not mean that the wrongs that occur on the way are morally 
justified. This relates to what I believe to be a certain moral dilemma facing marginalized philosophers and which I will now briefly discuss.

\section{Concluding Remarks: Marginalized Philo- sophers Embracing a Dilemma?}

Using a particular example, I have illustrated how harm injustice and disproportionate BAE can arise within the philosophical exchange of reasons.

The most reasonable way to mitigate the injustices I have discussed is to not proffer arguments that impose harm injustice or disproportionate BAE. We are all charged with this task. Being widely read in critical race theory, disability studies, queer theory, trans* theory, and so on, as well as becoming actively involved with, and attentively listening to, people who are oppressed within society surely helps, for it cultivates awareness of the ways that our theories and arguments can burden others.

There is a lingering doubt in my mind, however, concerning the complete eradication of the injustices I have discussed without a more major "overhaul" of the professional culture of philosophy, and so I will end on a somewhat pessimistic note. Tacit encouragement to put forward clever and "provocative" claims that are more likely to be published, and an excessive focus on logical-epistemic assessment of argumentation all contribute, I think, to a tendency to be somewhat careless with regards to the moral impacts of one's own argumentation. There are also blind spots in philosophers' awareness of intersectional axes of oppression and how ideas can impact these, fostered by a lack of willingness (and time) to go beyond strictly philosophical literature in one's own field. To my mind, this all points to a need for a more general—and perhaps quite radical—reform of professional institutions, culture, and practices. Yet, as Kristie Dotson points out, such changes to socially and historically entrenched practices and epistemological systems can be very difficult (2014).

Since change is likely very slow and incremental, what are members of marginalized groups who are philosophers to do in the meantime, when those who are not marginalized along similar axes produce burdening arguments? On the one hand, certain strategies of argumentation produce disproportionate $\mathrm{BAE}$, and may also be harmful or potentially harmful. On the other, some of those arguers directly exposed to the burdens and injustices by these problematic strategies are also those most likely to detect and expose them. This creates a dilemma. There is an urgent need to argue in these cases. But the argumentational engagement this involves will likely be disproportionately costly, and risky. Perhaps the willingness and competence to engage nevertheless, are signs of a valuable asset in the struggle against injustice and signal a kind of argumentational "burdened virtue" (Tessman 2005), the virtue of a person undertaking engagement, even as full enjoyment of the enticing goods on offer is denied to her.

\section{Endnotes}

1. I do not provide a full, detailed intersectional analysis of race and gender in this article, partly due to constraints of length, and partly because my reflections are based on the experiences that come from my subject position, namely, that of a white, trans woman (who belongs to the academic precariat). A full treatment of Tuvel's article would certainly require a more thoroughly intersectional lens that considers race, especially given how Tuvel closely intertwines issues of race and gender identity. I will, however, discuss some intersections with being trans, such as race, class, age, and disability, later in the article. For the purpose of this article, I understand transgender women or trans women as persons who were assigned as male at birth, but who identify as women.

2. For a useful sketch of analytic feminism and its uses, see Garavaso (2018) and Garry (2018).

3. It is clear that a general point could be made about how arguments concerning marginalized groups may disproportionately burden or harm members of those 
groups (people of colour, women, LGBT people, or those intersectionally positioned in any of these). I do not have the space to provide examples. The question of why such instances warrant the term "injustice" would need more development. Let me simply note two points on this subject. First, the argumentational injustices discussed here are objectionable harms or unfairness, or constitute the threat of objectionable harms or unfairness. Second, those affected are members of social groups, not simply individuals who happen to have certain sensibilities (such as in the case of an arguer who fears spiders considering an argument about spiders). The emotional burdens are linked in some causal way to social position. I would like to thank an anonymous reviewer for urging me to make this point clearer.

4. I would like to thank an anonymous reviewer for challenging me to better explain the "argumentational" character of this injustice.

5. One should note that Jenkins' own proposed corrective to Haslanger's account, involving the notion of "having a female gender identity," has itself been critiqued for being trans-exclusionary. See Andler (2017). The details of this further debate are not directly relevant to the present article.

\section{Acknowledgements}

I would like to thank Chloë Taylor, Ada Jaarsma, Eloy Rodriguez LaBrada, Namrata Mitra, Alison Suen, Sabrina Hom, Ani Dutta, Sarita Srivastava, and Rebecca Tuvel for helpful comments and input on the ideas contained in this article. Participants in the panel on Trans*feminist Philosophy at the American Philosophical Meeting in Chicago in 2018, in particular Saray Ayala, helped me refine many of my arguments and raised astute objections, for which I am very grateful. Thanks for helping me attain greater clarity on the issues are also due to my colleagues at Dalhousie, particularly to Tyler Hildebrand, Chike Jeffers, and Sue Sherwin.

\section{References}

Alcoff, Linda. 2006. Visible Identities: Race, Gender, and the Self. Oxford: Oxford University Press.

Andler, Matthew Salett. 2017. "Gender Identity and Exclusion: A Reply to Jenkins.” Ethics 135: 883-895.

Bach, Theodore. 2012. "Gender is a Natural Kind with an Historical Essence.” Ethics 122: 231-272.

Berenstain, Nora. 2016. "Epistemic Exploitation.” Ergo 3 (22): 569-590.

Berenstain, Nora. 2018. "Implicit Bias and the Idealized Rational Self.” Ergo 5 (17): 445-485.

Bermejo-Luque, Lilian. 2011. Giving Reasons: $A$ Linguistic-Pragmatic Approach to Argumentation Theory. Dordrecht: Springer.

Bettcher, Talia Mae. 2017a. "Response to Hypatia controversy over 'In Defense of Transracialism'." Learning Trans, May 5, 2017. Accessed, April 18, 2018. https://learningtrans.org/2017/05/06/taliabettcher-response-to-hypatia-coontroversy-over-indefense-of-transracialism/.

Bettcher, Talia Mae. 2017b. "Trans Feminism: Recent Philosophical Developments.” Philosophy Compass 12 (11). https://doi.org/10.1111/phc3.12438.

Bondy, Patrick. 2010. "Argumentative injustice." Informal Logic 30 (3): 263-278.

Borck, C. Ray 2017. “Negligent Analogies,” TSQ: Transgender Studies Quarterly 4 (3-4): 679-684.

Botts, Tina Fernandes. 2018. "Race and Method: The Tuvel Affair.” Philosophy Today 62 (1): 51-62.

Clare, Eli. 2009. Exile and Pride: Disability, Queerness, and Liberation, 2nd Ed. New York: South End Press.

Dotson, Kristie. 2011. "Tracking Epistemic Violence, 
Tracking Practices of Silencing." Hypatia 26 (2): 236257.

Dotson, Kristie. 2014. "Conceptualizing Epistemic Oppression.” Social Epistemology 28 (2): 115-138.

Dutta, Ani. 2017. "On Tuvel, Adichie, Dolezal and the Privilege-Identity Distinction." May 042017. Accessed May 11, 2018.

https://www.facebook.com/notes/ani-dutta/on-tuveladichie-dolezal-and-the-privilege-identitydistinction/10155234495464437/.

Fricker, Miranda. 2013. "Epistemic Justice as a Condition of Political Freedom?" Synthese 190: 1317-1332.

Garavaso, Pieranna. 2018. "What is Analytic Feminism?” In P. Garavaso (ed.), The Bloomsbury Companion to Analytic Feminism, 3-16. London: Bloomsbury.

Garry, Ann. 2018. "Why Analytic Feminism?” In P. Garavaso (ed.), The Bloomsbury Companion to Analytic Feminism, 17-36. London: Bloomsbury.

Gheaus, Anca and Lisa Herzog. 2016. "The Goods of Work (Other than Money!)" Journal of Social Philosophy 47 (1): 70-89.

Haslanger, Sally. 2012. Resisting Reality. Oxford: Oxford University Press.

Johnson, Ralph H. 2000. Manifest Rationality: A Pragmatic Theory of Argument. New York: Routledge.

Kapusta, Stephanie. 2016. "Misgendering and Its Moral Contestability." Hypatia 31 (3): 502-19.

McKinnon, Rachel. 2016. "Epistemic injustice." Philosophy Compass 11(8): 437-446.

Medina, José. 2011. "The Relevance of Credibility Excess in a Proportional View of Epistemic Injustice: Differential Epistemic Authority and the Social
Imaginary." Social Epistemology 25 (1): 15-35.

Micheli, Raphael. 2012. "Arguing Without Trying to Persuade? Elements for a Non-Persuasive Definition of Argumentation." Argumentation 26: 115-126.

Mikkola, Mari. 2009. "Gender Concepts and Intuitions." Canadian Journal of Philosophy 39 (4): 559-584.

Mills, Charles. 2005. “'Ideal Theory' As Ideology.” Hypatia 20 (3): 165-184.

Mohammed, Dina. 2016. "Goals in Argumentation: A Proposal for the Analysis and Evaluation of Public Political Arguments." Argumentation 30: 221-245.

Nordmarken, S. 2014. "Microaggressions.” TSQ: Transgender Studies Quarterly 1(1-2): 129-134.

Oliver, Kelly. 2017. "If this is feminism..." The Philosophical Salon, 08 May 2017. Accessed 07 June 2017. http://thephilosophicalsalon.com/if-this-isfeminism-its-been-hijacked-by-the-thought-police/.

Paglieri, Fabio and Cristiano Castelfranchi. 2010. "Why Argue? Towards a Cost-Benefit Analysis of Argumentation." Argument and Computation 1(1): 7191.

Peña-Guzmán, David M., and Rebekkah Spera. 2017. "The Philosophical Personality." Hypatia 32(4): 911 927.

Pohlhaus Jr., Gaile. 2014. "Discerning the Primary Epistemic Harm in Cases of Testimonial Injustice." Social Epistemology 28(2): 99-114.

Pulice-Farrow, Lex, Zakary A. Clements, and M. Paz Galupo. 2017. "Patterns of Transgender Microaggressions in Friendship: The Role of Gender Identity." Psychology \& Sexuality (8)3: 189-207.

Rooney, Phyllis. 2010. "Philosophy, Adversarial Argumentation, and Embattled Reason." Informal 
Logic 30 (3): 203-234.Schuessler, Jennifer. 2017. "A Defense of Transracial Identity Roils Philosophy World." New York Times, 19 May 2017. Accessed 07 June 2017. https://www.nytimes.com/2017/05/19/arts/adefense-of-transracial-identity-roils-philosophyworld.html?_r=0

Sealey, Kris. 2018. "Transracialism and White Allyship: A Response to Rebecca Tuvel." Philosophy Today 62 (1): 21-29.

Singal, Jesse. 2017. "This Is What A Modern-Day Witch-Hunt Looks Like." New York Magazine, 02 May 2017. Accessed 07 June 2017. http://nymag.com/daily/intelligencer/2017/05/transr acialism-article-controversy.html.

Stryker, Susan. 2015. "Caitlyn Jenner and Rachel Dolezal: Identification, Embodiment, and Bodily Transformation.” July 13 2015. Accessed 17 April 2018. http://blog.historians.org/2015/07/caitlynjenner-and-rachel-dolezal-identificationembodiment-bodily-transformation/.

Sue, D. W. 2010. Microaggressions in Everyday Life: Race, Gender, and Sexual Orientation. Hoboken, New Jersey: Wiley.

Tessman, Lisa. 2005. Burdened Virtues: Virtue Ethics for Liberatory Struggles. New York: Oxford University Press.

Tessman, Lisa (ed.). 2009. Feminist Ethics and Social and Political Philosophy: Theorizing the Non-Ideal. New York: Springer.

Tuvel, Rebecca. 2017a. "In Defence of Transracialism.” Hypatia 32 (2): 263-78.

Tuvel, Rebecca. 2017b. "What is It Like to Be a Philosopher?” May 17, 2017. Accessed 01 June 2018. http://www.whatisitliketobeaphilosopher.com/rebecc a-tuvel/.
Tuvel, Rebecca. 2018. "Racial Transitions and Controversial Positions: Reply to Taylor, Gordon, Sealey, Hom, and Botts." Philosophy Today 62 (1): 7388.

Winnubst, Shannon. 2017. "Why Tuvel's article so troubled its critics." The Chronicle of Higher Education, May 06, 2017. http://www.chronicle.com/article/Why-Tuvel-sArticle-So/240029. Accessed June 07, 2017.

Walton, Douglas N., and Erik C.W. Krabbe. 1995. Commitment in Dialogue: Basic Concepts of Interpersonal Reasoning. New York: SUNY Press.

Witt, Charlotte. 2011. The Metaphysics of Gender. Oxford: Oxford University Press.

Zack, Naomi. 2005. Inclusive Feminism: A Third Wave Theory of Women's Commonality. Lanham MD:

Rowman and Littlefield. 